\title{
Offshore middlemen: transnational intermediation in technology sourcing
}

\author{
Volker Mahnke ${ }^{1}$, Jonathan Wareham ${ }^{2}$, Niels Bjorn-Andersen ${ }^{3}$ \\ ${ }^{1}$ Department of Informatics, Copenhagen Business School, Frederiksberg, Denmark; \\ ${ }^{2}$ Department of Information Systems, ESADE, University of Ramon Llull, Barcelona, Spain; \\ ${ }^{3}$ Center for Applied ICT, Copenhagen Business School, Frederiksberg, Denmark \\ Correspondence: \\ J Wareham, Department of Information Systems, ESADE, University of Ramon Llull, Av. Pedralbes 60-62, \\ Barcelona 08034, Spain. \\ Tel: + 34932806 162; \\ Fax: + 34932048105 ; \\ E-mails: wareham@acm.org, Jonathan.wareham@esade.edu
}

\begin{abstract}
The tendency of acquiring information systems and other high technology services from international suppliers continues at unprecedented levels. The primary motivation for the offshore sourcing of technology and services continues to be labor cost arbitrage, and secondly, access to higher levels of expertise. Yet paradoxically, large gaps in technical proficiency, cultural values, and communication styles between client and vendor can undermine the overall success of the offshore relationship. This paper argues that a new breed of entities have emerged, brokering or intermediating offshore relations. The capabilities of such 'middlemen' include moderating disparities in expertise, culture, and communication styles that often deteriorate performance in offshore relationships. The paper presents a preliminary theoretical justification for the emergence of offshore intermediaries, describes how and why they develop boundary spanning capabilities, and offers a case study as initial evidence substantiating the function and processes in intermediating transnational offshoring relationships. Our theory development concludes with propositions concerning four major offshore intermediary capabilities: (i) intermediating cultural distance, (ii) intermediating cognitive distance, (iii) pre-contractual preparation and negotiation, and (iv) post-contractual operational management.
\end{abstract}

Journal of Information Technology (2008) 23, 18-30. doi:10.1057/palgrave.jit.2000124

Published online 29 January 2008

Keywords: offshoring; outsourcing; knowledge-work

\section{Introduction}

$T$ he migration of IT outsourcing relationships to lower cost regions such as India and China continues with few indications of abatement (King, 2005). The primary motivation for this trend continues to be labor cost arbitrage. However, a secondary incentive, higher levels of skill and specialization, is also cited more frequently in managerial discourse (Dedene and DeVreese, 1995; Pfannenstein and Tsai, 2004). Most of the offshoring literature studies the outsourcing firm (Mahnke et al., 2005), but there is also a growing and important body of literature focusing on the outsourcing vendor (Levina and Ross, 2003). This paper focuses on intermediation capabilities necessary to span boundaries between a client and an offshoring partner's value creation systems.

While firms are increasingly aware of offshoring possibilities, their ability to exploit them is far more limited. Frequently, the anticipated benefits in offshore outsourcing partnerships are not realized, complicated by lack of international experience, competency gaps (Cusumano, 2006), poor relational capabilities (Lane and Lubatkin, 1998), and cultural distance (Gopal et al., 2002; Sahay et al., 2003). As a consequence, organizations may reach out to an external provider of boundary spanning capabilities in order to traverse such gaps, that is, someone who can facilitate the exchange of expertise across two groups who hold different goals, values, and technical languages (Allen and Cohen, 1969; Aldrich and Herker, 1977; Tushman and Scanlan, 1981). Thus, we examine one possible method of how companies may successfully span such boundaries and thereby reduce many of the complexities of offshore relationships. 
A firm may require offshore intermediation capabilities that facilitate the advantages of offshore outsourcing while mitigating its most severe challenges; that is, dealing with the cultural, professional, and operational complexities of managing relationships across borders. Whenever such capabilities cannot be internally developed by a vendor or client, a third-party intermediary may be required. Accordingly, this paper examines the function of the offshore intermediary, a new breed of offshore 'broker' or 'middleman' providing offshore intermediation capabilities. Specifically, we offer novel empirical and theoretical insight to a largely unexplored area of offshore outsourcing by illuminating the question what offshore intermediaries do, and when in the offshoring process they add value to the relationship. While several authors mention the increasing importance of the phenomenon (Field, 2002; Rottman and Lacity, 2004; Rottman, 2006), there is a lack of theory development to systematically describe how offshore intermediation capabilities add value in the context of software development specifically, or offshore service provision in general.

Despite the prominent value-adding role of intermediaries in all sectors of the economy, the subject has commanded most attention in the financial literature (Rousseau and Wachtel, 1998) where intermediaries are effectively 'middlemen,' brokering transactions between buyer and seller (Rubinstein and Wolinsky, 1987). Intermediaries have been heralded for their ability to aggregate supply and demand, provide market transparency and liquidity, mitigate moral hazard and adverse selection by clearing transactions and providing trade financing, hold inventories to absorb variations in supply and demand, and re-bundle portfolios of goods and services across multiple suppliers (Rubinstein and Wolinsky, 1987; Spulber, 1999).

While many of the traditional functions of intermediation remain important for the facilitation of offshore systems development (e.g. coordinating multiple vendors), there are also important extensions that we attempt to define and explore in this article. In the realm of offshore systems development, a new breed of intermediary has emerged to moderate differences in culture, communication style, technical capabilities, and overall offshoring maturity. The task is one of intellectual, rather than financial arbitrage. Unlike trade in financial assets, intermediated services cannot rely on standard interfaces with structured technological syntax to the same degree (Lee and Kim, 1999; Mahnke, 2001; Mahnke et al., 2006). As such, offshore intermediaries offer a set of capabilities that are idiosyncratic to sourcing knowledge intensive services across international regions through a unique set of competencies. A crucial requirement is to establish 'structured technological dialogue' that allows clients to specify requirements, and permits vendors to trace interdependencies and impacts on overall system performance (Monteverde and Teece, 1995). Thus, one key task of the offshore intermediary is to develop inter-firm social and intellectual capital (Nahapiet and Ghoshal, 1998; Miranda and Kavan, 2005) to create interfaces allowing for inter-firm knowledge identification, knowledge-sharing, and knowledge-combination across company and cultural boundaries.

Consistent with traditional intermediation theory (Rubinstein and Wolinsky, 1987; Spulber, 1999), our argument acknowledges that in any form of exchange, parties have the option to transact directly with the other partner, or transact through an intermediary. A middleman will want some form of economic compensation for services, so the value that the intermediary provides should exceed the cost of using them. But just exactly where this tradeoff occurs is poorly understood. For example, Field (2002) argued that big companies like JP Morgan or General Electric have the scale and experience to directly transact with tier-one vendors in India (e.g. see discussion of The Bank of New York in Field, 2002). However, smaller companies are relegated to tier- 2 and tier- 3 providers, where quality decreases, and clients thereby incur substantially greater risks in managing an offshore partnership. As a result, it may be these situations that the intermediary justifies its costs. In fact, one optimistic estimate suggests that over half of all offshoring partnerships will be brokered or intermediated in the future as intermediaries make the offshore market more accessible to small and medium sized companies (Field, 2002).

An important point of clarification is that the functions provided by offshore intermediaries are boundary spanning capabilities that can be offered by a variety of organizational forms, be they internal, external or a combination thereof. The external market for offshore intermediaries seems to be converging around two main types. Law firms tend to be legal experts who specialize in contract formulation, enforcement, termination, dispute resolution, as well as the overall negotiation of terms and conditions prior to the contract formulation. In contrast, consultancies such as IBM Global Services or Cap Gemini bring domain expertise and process capabilities to the overall ongoing management of the offshore contract. Hence, where there is a tendency to group offshore intermediaries as either legal or operational this distinction is not entirely valid. Both consultants and law firms operate at many stages of the intermediation process, although there are natural specializations by individual firms.

As a first step towards a deeper understanding of offshore intermediation capabilities, this paper offers insights on how transnational intermediaries offer offshore intermediation services; learn from markets, institutions, suppliers, and clients in different locations; and how they use such learning to develop intermediated systems development across changing global market conditions. Specifically, we present preliminary evidence and theoretical arguments for four major intermediary capabilities: (i) intermediating cultural distance, (ii) intermediating cognitive distance, (iii) pre-contractual preparation and negotiation, and (iv) post-contractual operational management.

Accordingly, the remainder of the paper is structured as follows. The next section outlines the most pressing boundary spanning challenges that both client and vendor have to address when considering offshore development. The subsequent section employs a grounded theory-based analysis of a case intermediary and its interaction with three clients to offer initial evidence of the functions of the transnational intermediary. The penultimate section continues the theory building using evidence from the case study, and formulates propositions concerning the contingencies of offshore intermediation. We conclude the 
paper in the final section with a discussion of limitations, future research, and managerial implications.

\section{Offshore systems development: key challenges}

The literature on outsourcing IT partnerships is extensive and often highlights the unexpected complexities of managing outsourcing relationships (Earl, 1996; Mahnke et al., 2005). Frequently, the anticipated cost reductions promised in outsourcing partnerships are not realized due to unforeseen complications. Specifically, the costs of vendor search and contracting, quality assurance, conflict resolution, coordination of interdependencies, as well as overall relationship management and nurturance, are often cited as unanticipated challenges for those organizations recently initiated to the practice of outsourcing (Barthelemy, 2001; Lee et al., 2004).

Ågerfalk and Fitzgerald (2006) develop a framework that places these relative costs and benefits across different categories. Specifically, they suggest that global software development offers challenges and rewards in: (a) communication, (b) coordination, and (c) control of systems development because of: (i) temporal distance, (ii) geographical distance, and (iii) cultural distance. They specify the commonly perceived benefits of offshore system development as reduced cycle time from follow-the-sun development, access to a better skilled labor pool as well as best practice, and of course, reduced development costs. However, these benefits also have costs such as asynchronous communication, lack of face-to-face communication, reduced task awareness and shared vision, as well as cultural differences that lead to conflicts in communication styles, work practices, cooperation, values, and incongruent understandings.

Other authors echo the thesis that the recognized complexities of managing IT outsourcing partnerships can assume greater severity when conducted across international boundaries (Gopal et al., 2002; Sahay et al., 2003). In fact, a great deal of evidence suggests that spatial, temporal and cultural disparities between vendor and client are frequent sources of complication and dissatisfaction that further exacerbate the innate challenges in a purely domestic outsourcing relationship (Gopal et al., 2002; Murthy, 2004).

For example, Cusumano (2006) argues that despite the fact that 80 of the world's 117 SEI CMMI Level-5 companies are based in India, there are many hidden costs of offshoring systems development to India that erode the expected financial savings. These include travel back and forth to customer sites, competency disparities when formulating specifications, redoing work because of communications difficulties, or the constant re-work resulting from iterative development across geography and culture (Cusumano, 2006).

As an illustration, consider that many of the standard tools of systems development and design are premised upon a shared understanding and shared context (Sese et al., 2006). But formal methods (Zave and Jackson, 1997) that prescribe the use of mathematical logic as an avenue to formally specify and communicate user requirements may be insensitive to cultural disparities. And even though the language of mathematics is universal across cultures, its use in requirements specification varies substantially. However, more pragmatic and commercially applied approaches to systems development such as UML or agile development are clearly more sensitive to cultural disparities. For example, object-oriented design using UML (Booch et al., 1999) are premised on the idea that concepts have a clear and well-delimited meaning. As evidenced by Rumbaugh et al. (1991: 21): 'We define an object as a concept, an abstraction, or a thing with crisp boundaries and meaning for the problem at hand.' However, when asked to explain how universal classes are defined, Gabriel, a designer of an OO language, contends, 'That it is a fundamental question for which there is no easy answer. I try things' (Booch, 1994: 145). As such, common forms of commercial systems development assume the ontological existence of universal concepts, yet they are more pragmatic concerning the epistemology of identifying and delimiting classes. This ad hoc process of class definition is particularly sensitive to differences in culture, as pragmatic solutions emerge out of the local context. If the analyst and programmer do not share some basic interpretation and understanding of terms, classes or concepts, then misfits between an organization's requirements and the offshore solution are likely.

The classic body of theoretical discourse most relevant to this challenge is the literature on boundary spanners (Allen and Cohen, 1969; Aldrich and Herker, 1977; Tushman and Scanlan, 1981). The idea of boundary spanning has been applied generally in knowledge management (e.g. Cross and Parker, 2004; Carlile, 2004) and, in particular, the implementation and use of information systems (Levina and Vaast, 2005) and may contribute to our understanding what capabilities offshore intermediaries provide. Cross and Parker (2004), for example, define boundary spanners as 'vital individuals,' facilitating the sharing of expertise across two groups who hold different goals, values, and languages. Such individuals can assume different roles ranging from information processing, through interpreting and translating knowledge, to negotiating meaning and transforming knowledge (Carlile, 2004). When engaging separate groups in dialogue, boundary spanners may use 'boundary objects' (e.g. Star, 1989; Boland and Tenkasi, 1995; Carlile, 2002; Bechky, 2003), which provide a common reference point to coordinate distributed work among heterogeneous actors (Star, 1989). For example, Boland and Tenkasi (1995) suggest that boundary objects may be narratives developed in work practices to facilitate a shared frame of reference among individuals. However, role conflict will emerge, for example, when boundary spanners apply an information processing approach where a knowledge transformation approach would be warranted (Carlile, 2004; Wareham et al., 2007).

While the boundary spanning literature is clearly relevant in providing a higher level conceptualization of negotiating relationship across cognitive or cultural gaps, it has been largely focused on how individual agents become, and function, as boundary spanners (Levina and Vaast, 2005). Our purpose is to extend the general concepts of boundary spanning and to apply them in a very specific type of organization, the offshore intermediary. Our main research questions follow.

1. What value adding capabilities do offshore intermediaries provide?

2. Under what circumstances are clients more likely to engage in intermediated offshore relationships $v s$ direct ones? 
As mentioned, the literature concerning boundary spanning is relatively mature. However, the theoretical and empirical literature addressing offshore intermediation is limited. Accordingly, we proceed by presenting a case study of an offshore intermediary in a grounded theory building exercise that will help address our research questions.

\section{Case exemplar: offshore intermediation}

The following section presents initial evidence to substantiate a framework for offshore intermediation emerging from our study. The case follows with a discussion and formulation of propositions.

\section{Method}

The data were collected by two researchers throughout the year 2006 from interviews with the case company as well as three of its major clients. Eight informants from the case company included the CEO, CIO, two project lead managers and a number of line employees. We intentionally spoke to informants at different levels of the organization in order to assure data representativeness and sampling data from stratified sources that appropriately represented the organization or the phenomenon studied. Towards this goal, we also interviewed three major clients from different sectors including security, financial services, and health care. In addition to personal interviews, other sources of primary data included telephone interviews and email correspondence. Finally, archival data, such as company internal documents and websites were also employed by the third researcher to corroborate the findings of the first two researchers across the case study and provide internal control for researcher bias.

The data were coded using guidelines from the Straussian tradition of grounded theory (Strauss and Corbin, 1990). Grounded theory is an especially useful methodology to employ when a phenomenon has been little explored. The Straussian tradition encourages the researcher to employ prior knowledge and understanding (e.g., literature from related disciplines) to shed light on the phenomena being examined, in contrast to the Glaserian tradition, where the researchers draw conclusions entirely from the data (Glaser, 1992). In this case, prior understanding from the offshoring, outsourcing, project management, and intermediation literature guided our investigation.

We created 'open' codes initially to identify patterns in the data and steadily refined the codes as our understanding of offshore intermediation increased. We converged upon four top-level codes and several layers of sub-codes within them. Briefly, the codes were: (i) cultural differences, (ii) cognitive distance, (iii) offshore preparation (pre-contractual), and (iv) offshore operations (post-contractual).

Cultural differences were derived from the cultural anthropology research. Specifically, we employed the seven top-level dimensions of Trompenaars and Hampden-Turner (1997), widely considered a successful extension of the seminal research of Hofstede (1980). These dimensions included: universalism $v s$ particularism; individualism $v s$ communitarianism; specific $v s$ diffuse; affective $v s$ neutral; achievement $v s$ ascription; and sequential $v s$ synchronic time perception.
Codes for cognitive distance were based predominantly in the key process areas as identified in the CMMI models (SEI, 2005), as well as issues that normally are addressed in project management literature (Keil and Mann, 2000). These included concepts from CMMI such as requirements management, project planning, quality assurance, configuration management, organization process focus, and organization process definition.

Codes for pre-contractual preparation centered on the process that the intermediary employs to ready the client for the offshoring partnership. These included: vendor search, internal project champion creation, contract formulation, project and requirements specification, documentation, and interdependencies management.

Codes for post-contractual operations included communication processes, quality measurement and control, conflict resolution, tracking and oversight, specification change, documentation, training, peer reviews, and others.

Informant opinions were controlled by circulating a preliminary copy of the research findings among the interview respondents. We also held a number of followup interviews via email and telephone in order to solicit qualifications and criticism to our initial conclusions in order to correct for researcher bias and increase the internal validity of the qualitative research.

Table 1 highlights exemplary challenges and responses offered by the offshore intermediary from a temporal perspective that is both pre-and post-contractual.

We follow with a similar breakdown of the boundary spanning forms that mitigate cultural and cognitive distance. We present these separately because they are in many ways orthogonal; that is, equally relevant to both preand post- contractual phases (Table 2).

\section{Case evidence: I-technologies}

I-Technologies is an IT consultancy specializing in matching Scandinavian clients with offshore service providers founded in 1999. A central emphasis is facilitating cultural and professional connections to new markets and software development opportunities and providing project management and contract management services.

A variety of unsuccessful offshoring ventures has lead I-Technologies to the conclusion that most clients are totally unprepared for any type of offshore relationship. As such, the company has focused its efforts on three main functions: (a) project scope definition and requirements specification, (b) development of project management and communication skills, and (c) formulation of contracts, quality criteria, and conflict resolution.

One of the first intermediation clients who approached I- Technologies in 2001 was a leading Danish security firm DANSECURE. DANSECURE is now well under way with the first offshore outsourcing efforts. Before turning to I-Technologies, the IT manager of DANSECURE explained: 'We had already asked our present supplier if they could outsource some of the tasks to countries with low costs. Everybody has been very positive towards the idea and, if everything turned out fine, I imagined that half of our outsourcing was soon taken over by sub-contractors in low cost countries.' 


\begin{tabular}{|c|c|c|c|c|}
\hline Phase & Description & Problems addressed & Responses & Value adding activities \\
\hline $\begin{array}{l}\text { Pre-contractual: } \\
\text { Prepare clients } \\
\text { for offshoring } \\
\text { relationship }\end{array}$ & $\begin{array}{l}\text { Formalized process under which } \\
\text { intermediary works intensively } \\
\text { with client to prepare for } \\
\text { interaction with offshore vendor }\end{array}$ & $\begin{array}{l}\text { Inability to identify } \\
\text { appropriate vendors, } \\
\text { Inability to define and } \\
\text { delimit projects, } \\
\text { Lack of skills to codify } \\
\text { requirements, } \\
\text { Lack of experience in } \\
\text { negotiating contract } \\
\text { terms }\end{array}$ & $\begin{array}{l}\text { Project definition and pilot; mapping the detailed } \\
\text { requirements; product documentation; vendor } \\
\text { search; contract formulation and negotiation. } \\
\text { systems development tools such as gap analysis, } \\
\text { UML, requirements specification, as well as } \\
\text { possible organization/process reengineering. In } \\
\text { addition, intermediary knows to 'ask right } \\
\text { questions' }\end{array}$ & $\begin{array}{l}\text { Experience augmentation, } \\
\text { Managing expectations, } \\
\text { Creating relational awareness }\end{array}$ \\
\hline $\begin{array}{l}\text { Post-contractual: } \\
\text { Manage offshore } \\
\text { operations }\end{array}$ & $\begin{array}{l}\text { Brings operational experience } \\
\text { and best practice in managing } \\
\text { offshore development. Tools of } \\
\text { project and client management } \\
\text { are marshaled to monitor quality } \\
\text { and service, provide mechanisms } \\
\text { of conflict resolution, project } \\
\text { scope management and project } \\
\text { termination }\end{array}$ & $\begin{array}{l}\text { Lack of project } \\
\text { management skills, } \\
\text { Lack of quality } \\
\text { control skills, } \\
\text { Integration of off-site } \\
\text { code into legacy } \\
\text { systems, } \\
\text { Need to monitor quality } \\
\text { standards }\end{array}$ & $\begin{array}{l}\text { Assist project management for client; identify a } \\
\text { champion from client who will take command of } \\
\text { the project; identify the actual project } \\
\text { management; assistance in vendor management; } \\
\text { establish clear communication channels and } \\
\text { policies; evaluate and modify work collaborative } \\
\text { processes; contract formulation with definition of } \\
\text { outcomes, measures, and quality control; define } \\
\text { processes of conflict resolution }\end{array}$ & $\begin{array}{l}\text { Avoiding experience traps, } \\
\text { Neutralizing collaborative failure } \\
\text { sources, } \\
\text { Maintaining relational awareness }\end{array}$ \\
\hline
\end{tabular}

\section{Pre-contractual} Prepare clients for offshoring

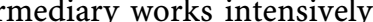
with client to prepare for

\section{nal experience and best practice in managing project and client management are marshaled to monitor quality dervice, provide mechanisms scope management and project}

Inability to identify opriate vendors, ity to define an requirements,

ack of experience in egotiating contract manement; assistance in vendor management; sources ources

Maintaining relational awarenes

Table 2 Boundary spanning forms: cultural and cognitive

\begin{tabular}{|c|c|c|c|c|}
\hline Function & Description & Problems addressed & Response & Value adding activities \\
\hline $\begin{array}{l}\text { Intermediate } \\
\text { cultural } \\
\text { distance }\end{array}$ & $\begin{array}{l}\text { Intermediates differences in culture } \\
\text { that are manifested in communication } \\
\text { styles (high and low context } \\
\text { communication), individualism } v s \\
\text { collectivism, and temporal sense } \\
\text { (linear } v s \text { poly-synchronous time } \\
\text { perceptions) and other cultural } \\
\text { differences that would significantly } \\
\text { impact the likelihood of a successful } \\
\text { off-shoring relationship }\end{array}$ & $\begin{array}{l}\text { Lack of cultural } \\
\text { understanding, } \\
\text { Inability to } \\
\text { communicate } \\
\text { effectively, } \\
\text { Inability to interpret } \\
\text { cultural symbols }\end{array}$ & $\begin{array}{l}\text { Intermediary maintains staff with nationalities } \\
\text { from both regions. This staffs are experienced in } \\
\text { foreseeing common disparities in } \\
\text { communication, work and thought styles of the } \\
\text { two (or more) regions }\end{array}$ & $\begin{array}{l}\text { Mapping cultural differences, } \\
\text { Cultural training and specialized } \\
\text { translations } \\
\text { Determining associated } \\
\text { knowledge transfer costs }\end{array}$ \\
\hline $\begin{array}{l}\text { Intermediate } \\
\text { cognitive } \\
\text { distance }\end{array}$ & $\begin{array}{l}\text { Intermediates differences in relative } \\
\text { skill levels that might prohibit } \\
\text { successful communication and } \\
\text { common understanding between client } \\
\text { and vendor. Well-known example is } \\
\text { CMMI levels. CMMI Level-5 providers } \\
\text { work in highly systematic and } \\
\text { structured way that may clash with } \\
\text { clients' less formalized work style }\end{array}$ & $\begin{array}{l}\text { Lack of awareness of } \\
\text { system requirements, } \\
\text { Inability to outline } \\
\text { budgets and } \\
\text { timeframes, } \\
\text { Misunderstanding with } \\
\text { regards to } \\
\text { documentation } \\
\text { requirements }\end{array}$ & $\begin{array}{l}\text { Intermediary has experience with CMMI } \\
\text { systems and actively employs staff who have } \\
\text { worked in CMMI Level-5 organizations. These } \\
\text { professionals are technical specialists } \\
\text { functioning as liaisons between the highly } \\
\text { systematic CMMI } 5 \text { vendor and less specialized } \\
\text { clients who would have difficulties speaking a } \\
\text { similar 'technical language' }\end{array}$ & $\begin{array}{l}\text { Specialized translations between } \\
\text { client's perceived needs and } \\
\text { vendor's requirements, } \\
\text { Codifying interfaces so that } \\
\text { specifications can be crafted, } \\
\text { Creating common ground to } \\
\text { facilitate understanding }\end{array}$ \\
\hline
\end{tabular}


However, after unsuccessful attempts with direct offshore solutions with Indian vendors during 1999-2002, the same manager commented, 'We have chosen to outsource the outsourcing. Of course, the extra link via I-Technologies makes the assignment more expensive. It would probably be possible to save something by arranging it all by ourselves, but we do not have the critical mass or the desire to move into an area where we do not have any experience' (DANSECURE IT Manager). Today, the security firm estimates that it saves $33 \%$ on the solutions completed in India. The Indian employees spend more time on solving a task, but the price per hour is much lower. Consequently, total costs are lower while the system development quality matches or exceeds local levels. On the other hand, 'there are extra costs that we have to include, for example, system specifications, translation of documents, and the extra coordination time' (DANSECURE Financial Controller).

By contrast, not engaging I-Technologies services means that 'clients would incur substantial vendor selection costs, system transition costs, costs associated with cultural and professional training of employees, as well as contract management costs and significant travel and re-location expenses' (I-Technologies Project Manager). Of course, 'over time, clients learn to do things we provide, and they may seek to cut us out of business as they learn how to deal with the Indian's; but this is an inevitable part of the life as an intermediary like us' (I-Technologies Founder).

The goal of I-Technologies is to help the outsourcing company partially recover these costs. As I-Technologies responsible manager for the DANSECURE cooperation explains, 'Our experience has shown that we need some kind of cultural interface when managing offshore contracts. Scandinavians communicate directly and have little social hierarchy. Indians, on the other hand, have a hierarchical culture. Furthermore, Indians prefer not to say no to anyone and will often say yes - meaning "yes I understand you," not "yes, I agree - we will have this done on time.' I-Technologies solution to this is to hire Indians and bring then on site in Scandinavia. At the same time, I-Technologies provide Scandinavian clients with a Scandinavian interface manager situated in India. In this manner, staff from both regions work side by side and develop common ground, and '...their common experience allows them to foresee and avoid problems that might result from miscommunication' as an Analyst of I-Technology comments.

Another customer of I-Technologies, the major financial service provider SCANCARD, experienced a distinct problem with disparities in working styles. 'A CMMI level 0 or 1 organization like us will be less formal in documenting the development process, changes, etc. This means that there is much more ad hoc problem solving which can result in sloppy, but functional code' (SCANCARD IT Manager). As a response, I-Technologies also hire developers who have experience working for or with CMMI Level-5 developers. CMMI was developed to create consistent quality levels across a large set of military contractors writing very complicated code, but ' ... most programmers from us would find working with CMMI level 5 development houses cumbersome and overly formalized. For most businesses, this is pure overkill' (SCANCARD IT Manager).

The role of the intermediary with CMMI Level-5 development vendors is not to program, rather, they help in the requirements specification and change requests phase to translate the requirements of the client into the language of the code developers. In iterative development, they help liaison between client and vender. 'Our clients frequently do not understand the necessity of all the demands made by our developers. They see them as excessively thorough. Our job is to bridge this gap, communicate to both sides in their own terms, as well as to ensure consistent expectations, understanding, and translation to reach overall compatibility in the relation' (I-Technologies Project Manager).

The first main function encompasses many of the tasks normally addressed in common systems development methodologies. Here, I-Technologies complete a thorough analysis of the motivations (labor arbitrage, access to expertise, etc.), defining project scope, interdependencies, and detailed specifications. As one of the lead mangers stated, 'We often encounter clients who simply have not understood their own motivations for the offshore move. This is doomed to fail by definition, because nobody in the organization has determined what might constitute success.' Accordingly, I-Technologies see one of its key value adding functions in overcoming difficulties of delimiting the project scope. 'Most clients think off-shoring is just a matter of picking up the phone and ordering. They have become quite surprised with the amount of time it actually takes us to ask the right questions, and define a project that is constrained but feasible. As technology consultants, we have experienced this time and time again, and our clients are always taken back by what a lengthy process requirements specification actually is' (I -Technologies Project Manager).

The second main function relates to the fact that new systems require some kind of change in organizational processes, where it is important to develop the management's internal project management and communication skills. 'With big projects requiring new processes, there is a huge risk that we manage the offshore development that produces great software, but then it all falls to the ground once we deliver it. Unfortunately, we have had to learn this the hard way' (I-Technologies Project Manager). Accordingly, I-Technologies will often invest considerable resources in educating the client's management with the appropriate change management tools. Here, classical reengineering methods (e.g. Hammer, 1995) are applied in order to ensure that the processes are aligned with the software, and that visible project leaders are given adequate communication skills to manage the organizational transformation. 'We can coordinate the development of software that is both inexpensive and sophisticated, but if we deliver it to a client that does not know what to do with it, it makes little difference' (I-Technologies Project Manager).

The third and perhaps least appreciated function of I-Technologies is in vendor management, where cultural intermediation is required in the translation between the two parties, for example, offshore contract formulation, especially because the definition of verifiable quality criteria tenable to international law enforcement often remains elusive. Given the frequently substantial cognitive and cultural distance, the likelihood of unfulfilled expectations concerning function and quality is high. Contract enforcement is complicated in lieu of some objective 
quality criteria that can be understood and verified by both client and vendor. The case informants emphasized that the processes for conflict resolution are paramount to the success of the relationship, and are often neglected in offshoring contracts. 'It is not a question of if, but when the conflict is going to happen and how we are going to handle it. This can make the difference between a small bump in the road and a full blown legal fight. Experience has told us that well functioning conflict resolution procedures are probably the most critical tool in any offshore development project' as the CIO of PROHEALTH, a major client in the insurance sector, comments.

As an intermediary, I-Technologies is often not in a position to negotiate conflict resolutions between client and vendor. The risk is too large that clients view them as agents of the vendor, and many vendors view them as agents of the client. In these cases, important intermediation services include the establishment of governance structures and communication channels so that conflicts are detected quickly and arbitration is effective. In the case of PROHEALTH, where multiple offshore vendors are employed, I-Technology assumes coordination of vendors and sub-contractors via a local delivery center in India. Such localized handling of several Indian sub-contractors includes a phase of identification and negotiation with set of potential vendors and sub-contractors in local market. In instances, where multiple sub-contractors are employed, I-Technology adds value by managing interdependencies and any conflicts to guarantee a 'seamless' and coherent process for PROHEALTH across many suppliers.

Not all clients of I-Technologies exhibit an exclusively positive experience with offshore-intermediation services provided by I-Technologies. A Swedish fashion retailer, for example, after a short time using the intermediary, cancelled the contract: 'Our reason for hiring I-Technologies was to have a scout into alien territory; our goal was, over time, to learn the territory ourselves... Despite having been open about this, we found I-Technologies was trying to prevent us from learning and adapting to the Indian partner.' Another former client, NORDBANK, voices similar concerns: 'Our goal is to become able to scale up our offshore operations rapidly, but I-Technologies seems to slow us down in this effort, we wonder whether higher investments upfront would have enabled us to learn faster later on, but now it is hard to say.' One director at I-Technologies commenting on these cases argues: 'Admit- tedly, we had a rapid growth and at times our client's demands outpaced our ability to serve their needs... and it is also a growing reality that clients require direct contacts to clients, thus, increasingly we are acting as an enzyme like business model. We facilitate complex offshore relations on an ongoing basis. Accordingly, we seek to migrate with our client needs towards shorter term and simultaneously more complex projects.'

\section{Theory building}

The theoretical analysis and the empirical insights obtained from the grounded approach used in analyzing the case study will be presented in three sections: (a) theoretical framework, (b) propositions regarding the value of transnational intermediaries, and (c) interdependencies.

\section{Theoretical framework}

Our analysis led us to summarize that the disparities needing intermediation capabilities first of all could usefully be grouped into cultural and cognitive factors. Secondly, we found that it was useful to distinguish between contract negotiation and in the operational period where the work is completed. The grounded work in I-Technologies corroborated the view that these two dimensions were indeed relevant in making sense of the case. Accordingly, we propose the following theoretical framework as shown in Table 3. This is a $2 \times 2$ matrix with cultural/cognitive on the one dimension and pre-contractual/post-contractual on the other. In order to prepare for the discussion following, we have furthermore indicated that we will propose four sets of propositions, to be discussed in the next section, followed by a discussion and a fifth set of propositions concerning interdependencies.

\section{Propositions regarding the value of transnational intermediation}

\section{Cultural disparities}

The first major function that we have identified for transnational intermediaries is the mitigation of cultural disparities. Our case demonstrated that cross-cultural tensions are a frequent source of turbulence in offshoring partnerships. As such, the intermediary responded by hiring staff that represent all concerned national regions,

Table 3 Framework of intermediary functions

\begin{tabular}{|c|c|c|c|}
\hline & & Propositions III & Propositions IV \\
\hline & & Pre-contractual & Post-contractual \\
\hline Propositions I & Cultural distance & $\begin{array}{l}\text { - Vendor search to ensure cultural } \\
\text { compatibility } \\
\text { - Establish communication channel } \\
\text { and cultural liaisons }\end{array}$ & $\begin{array}{l}\text { - Co-located cultural liaisons } \\
\text { mitigate misunderstanding } \\
\text { - Clearly defined processes for } \\
\text { communication and coordination }\end{array}$ \\
\hline Propositions II & $\begin{array}{l}\text { Cognitive } \\
\text { distance }\end{array}$ & $\begin{array}{l}\text { - Project scope definition } \\
\text { - Common expectations }\end{array}$ & $\begin{array}{ll}\text { - } & \text { Project management and } \\
\text { - } & \text { Quality Monineering skills } \\
\text { - Change Management } \\
\text { - Conflict resolution }\end{array}$ \\
\hline
\end{tabular}


thereby bridging any dissonance caused by communication style differences.

The cultural gaps between Northern Europe and India are generally well documented (Trompenaars and Hampden-Turner, 1997). For example, highly individual cultures, such as Anglo-American or North European, tend to use low-context communication where the information (message) is very explicit. Individuals will typically shape their thinking and communication as if it was addressed towards themselves. By contrast, collectivist cultures, such as Asian, tend to use high-context communication with more implicit information. Collective thinking and communication emphasizes the needs of the group more than the individual, and this significance is seen in the information exchanged (Hofstede, 1980; Trompenaars and Hampden-Turner, 1997). Accordingly, it is well documented that divergent cultural patterns (cultural distance) can lead to inefficient communication (Te'eni, 2001; Markus and Kitayama, 1991).

However, the manner in which they manifest friction in a transnational client-vendor work relationship is more subtle (Markus and Kitayama, 1991). Unless the outsourcing firm understands and manage these differences in the initial search, the contract negotiation phase, and later in the ongoing business relationships, substantial conflicts are likely to arise and erode the potential benefits. While it is easy to acknowledge differences in social hierarchy or temporal perception intellectually, normative solutions to the disparities are more elusive. Specific cultural knowledge is costly to transfer, as it is locationspecific or 'sticky' to the geographic, organizational or institutional context in which it was created (von Hippel, 1988; Wareham and Gerrits, 1999). Accordingly, transnational intermediation must be responsive to the type of knowledge and its implicit transfer costs (Kogut and Zander, 1992; Armbrüster \& Kipping, 2003). As such, the intermediary with experienced staff and culturally aware managers from both regions can more easily foresee and transgress well-known differences in work and communication patterns caused by disparities in communication styles and values.

By mapping and creating awareness of the consequences of cultural differences in the process of cross-border system development, the relevant drivers of knowledge transfer costs can be understood and influenced. In addition, especially in the case of de-novo entry in offshore location, the intermediary can mitigate cultural entry barriers. For instance, the intermediary can influence how long it takes for the offshore business model to become operative from the initiative to a working project organization. Moreover, the intermediary can assist in defining how much a client has to invest initially to establish an offshore relationship. Transnational intermediation capabilities may also create value through compressing cycle times by minimizing cross-cultural entry barriers. Accordingly, we suggest the following propositions:

P1a: Transnational offshore intermediation capabilities add value through reducing the costs of cultural disparities.

P1b: Client's whose staff is less experienced in dealing with cross-cultural issues will benefit more from the use of a third-party intermediary than clients whose staff is more experienced in dealing with cross-cultural issues.

\section{Cognitive distance}

The second function of transnational intermediaries is the mitigation of cognitive distance. Te'eni defines cognitive distance as the initial gap between the sender and receiver's interpretations before transmitting the messages (Te'eni, 2001: 282). This can result from differences in current information or from different ways of thinking and communicating. In an offshoring context, cognitive distance often arises when relatively lesser-skilled clients attempt to access a high level of expertise at comparatively lower costs (Mahnke et al., 2005). This is precisely where an offshore intermediary can add value.

Task coordination in offshore outsourcing benefits from a large and consistent 'shared knowledge set' about problems and possible solutions (Mahnke and Overby, 2007). However, great expertise differentials between outsourcer and vendor can often hinder collective knowledge sharing, introduce cognitive distance and, consequently, complicate cross-border knowledge sharing (Argote, 1999). Specifically, with most of the CMMI Level-5 development houses being located in India (Cusumano, 2006), the differences between working styles here and in western companies can be large. Through time, CMMI has grown to be considered exclusively virtuous, the higher evaluation the better. However, the very high level of structure and formalization comes at a price, and it is often excessive for most business needs, where a possibility for modification after testing and flexible response is advantageous. The transnational intermediary helps transgress and translate the working requirements and styles of both parties.

Whereas codified knowledge often results from abstraction and establishing cause-effect relations expressed in written form, un-codified knowledge often results from local experience, is context-dependent, and remains embodied in the firm's employees (von Hippel, 1988). As such, one can expect that the larger the proportion of uncodified knowledge, the more costly interface identification and inter-firm system integration. Thus, intermediaries create value by articulating and codifying interface knowledge to decrease the client's costs of knowledge transfer. The offshore intermediary adds value by offering specialized translations between perceived client needs and vendor requirements, codifying interfaces so that contracts can be crafted and systems can be connected, as well as creating sufficient common ground to facilitate understanding and avoiding conflict (Monteverde and Teece, 1995, Mahnke et al., 2006). Mitigating differences in systems development methods or styles, our case company accomplished this by hiring analysts and developers with substantial experience with CMMI vendors. Accordingly, we suggest the following propositions:

P2a: Transnational offshore intermediation capabilities add value through reducing the costs of cognitive distance.

P2b: Clients who have significant differences in their approach to software development compared to their offshore vendors will benefit more from the use of the intermediary than clients who do not. 


\section{Pre-contractual}

The third major function of transnational intermediaries is a comprehensive preparation of the client for an offshoring relationship. Many of the fiascos in offshoring can be traced to the fact the client was not appropriately prepared for the offshoring outsourcing relationship due to a lack of prior experience (Willcocks and Lacity, 1998). Some of the outsourcing relations that Lacity et al. (1995) examined experienced disastrous results because they lacked the expertise to select vendors, evaluate vendor's past performance, and to negotiate sound contracts. As they suggest, a company cannot control what it does not understand and the client's preparedness cannot be assumed, neither on an organizational nor application level.

The activities through which transnational intermediaries help prepare clients for offshore system development include creating awareness of the offshoring objectives, developing analytical understanding of organizational and programmatic interdependencies, and a joint and explicit evaluation of the relevance of the client's and vendors prior experience for current joint offshoring project. In addition, opening parochial and ethnocentric mindsets will create awareness of the possibilities and limitations of experienced and planned offshore software development activities. Transnational offshore intermediation adds value by establishing common expectations, defining project scope and contractual mechanisms. Table 1 highlights a number of the specific actions used by our case intermediary that include: project definition and detailed requirements specification, vendor search, contract formulation, and negotiation. Accordingly, we suggest the following propositions:

P3a: Transnational offshore intermediation capabilities add value by preparing the client for offshoring partnerships (pre-contractual intermediation).

P3b: Clients who have little experience in offshore vendor identification, screening, selection, requirements specification, and contract negotiations will benefit more from a third-party intermediary than clients who do have more experience.

\section{Post-contractual}

The fourth major function of the transnational intermediary is to act as a process facilitator in the going-concern between offshore-vendor and its clients. An offshore relation is not a static affair, but an ongoing learning process of mutual adaptation. In the offshore development process, unforeseen disagreements occur, which can trigger a process of hidden conflict impeding smooth interaction. This opens the door to post-contractual haggling and misunderstanding (Williamson, 1996) and simultaneously stresses the importance of psychological contracts in governing offshore outsourcing relations (Miranda and Kavan, 2005). Hence, not only is contract formulation critical, but defining objective deliverables and measurable performance/quality criteria requires considerable prior shared knowledge - be it in the form of intellectual or social capital (Nahapiet and Ghoshal, 1998).

Whenever guaranteeing measurable project outcomes is impossible between parties, the transnational intermediary creates value by formulating a process that can detect misunderstanding and resolve pending conflicts efficiently (Barzel, 1982). Hence, the transnational intermediary can be instrumental in defining the process of conflict resolution (Dyer and Singh, 1998) such that parties can quickly resolve differences and avoid costly litigation across multiple legal systems and consequent project delays.

In this case, the intermediary mediates the conflict by identifying and surfacing the cultural and cognitive disparities (e.g. explicit $v s$ implicit communication styles, formal $v s$ informal work styles). The intermediary then creates relational awareness by explicating assumptions and defining a common vocabulary from which joint future action can proceed (Carlile, 2002, 2004). Previous experience, especially when tacitly accumulated in diverse contexts and projects, may also lead to superstitious learning and erroneous inference between past failure/successes and future courses of action. As such, by explicating implicit assumptions, the intermediary helps reduce the negative effects of experience traps.

Finally, depending upon the scope of the project, the client may not be equipped with the necessary internal project management skills within his/her own organization to spearhead an externally developed project. Here the intermediary may work with the client to ensure that the appropriate communication channel, implementation skills, and structures are present in-house, so that interfirm governance structures can be tailored to relational requirements (Dyer and Singh, 1998). Through the continuous nurturing of cooperative skills, collaborative failure sources are neutralized and relational awareness can be developed. Thus, offshore intermediation capabilities mitigate process conflict and misunderstanding caused by spatial differences and knowledge partitioning (co-location, etc). Accordingly, we propose the following propositions:

P4a: Transnational offshore intermediation capabilities add value by managing ongoing offshore partnerships and operations (post-contractual intermediation).

P4b: Clients will benefit more from third-party intermediation the lower their experience in complex project management, formalized conflict resolution, quality evaluation, and systems integration skills.

\section{Interdependencies}

In considering the framework and the propositions, it is important to stress that pre- and post- contractual value creation by transnational intermediaries are richly interrelated, as are the processes of mitigating cultural and cognitive distance. For example, insufficient preparation, erroneous expectations, and lacking self-awareness can result in an increased likelihood of post-contractual haggling and conflict. Likewise, greater cultural misunderstandings normally exacerbate technical miscommunication. As such, we transpose the pre- and post-contractual intermediation categories against the cultural and cognitive in an effort to trace the interdependencies. While this representation only superficially highlights how the functions interrelate and reinforce each other, it does indicate 
how the emphasis on one stage can render benefits in the other (Figure 1).

Pre-contractual intermediation can help mitigate the problems of cultural distance through optimal vendor search, where cultural compatibility is emphasized. The experience of the intermediary in common cultural conflicts will facilitate affective focus on the technical aspects that plague all outsourcing arrangements. Moreover, co-located cultural liaisons facilitate contract formulation and language choice that is suitable to both client and vendor and their relative legal systems. In a similar fashion, pre-contractual intermediation will emphasize the technical disparities that are likely to be contentious between client and vendor. The intermediary's experience will guide pre-contractual negotiations to form project scope and expectations that are feasible, service levels and operational metrics that are objective and measurable, as well as project management procedures to avoid project scope creep and divergent expectations. These carefully executed phases of client preparation are clearly correlated with a higher probability of fulfilled expectations. Accordingly, we propose the following proposition:

P5a: Clients who engage a third-party intermediary at an early stage (pre-contractual) will experience a reduced likelihood of problems in the operational (post-contractual) stage of the offshore partnership.

P5b: Clients who engage a third-party intermediary to mitigate the problems of cultural distance will experience a reduced likelihood of problems of cognitive distance.

P5c: Clients who engage a third-party intermediary to mitigate the problems of cognitive distance will experience a reduced likelihood of problems of cultural distance.

\section{Discussion and conclusion}

Unlike financial intermediation, the intermediation of offshore systems development work cannot be understood as the simple exchange of well-defined products or instruments. It is a task of intellectual, rather than financial arbitrage, and is often riddled by complications of cultural and professional distance, as well as disparate international experience of parties involved. Accordingly, we argue that there is a need for boundary spanning capabilities in offshore systems development partnerships - a need that can be fulfilled by offshore intermediaries. We have provided theoretical arguments and preliminary evidence for four major intermediary functions: (i) intermediating cultural distance, (ii) intermediating cognitive distance, (iii) preparing client for offshoring relationship (pre-contractual intermediation), and (iv) managing offshoring relationship (post-contractual intermediation).

We contribute to the IS outsourcing literature by identifying a new role in offshore system development efforts. Rather than taking the perspective of the offshore vendor or client as in previous research, we provide a novel view of the offshore middleman. As mentioned, some estimates suggest that more than $50 \%$ of all offshoring partnerships will be brokered by intermediaries in the

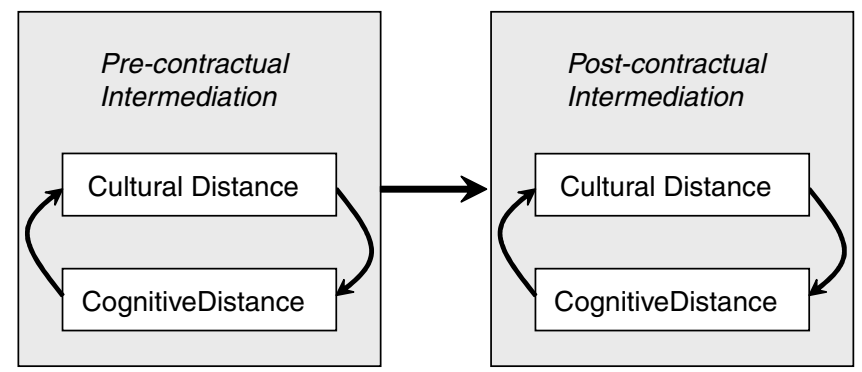

Figure 1 Interdependencies of Offshore Intermediation (Propositions 5).

future (Field, 2002). While the phenomenon has been mentioned in the previous offshoring literature (Field, 2002; Rottman and Lacity, 2004; Rottman, 2006), it has, to our knowledge, yet to receive in-depth empirical or theoretical attention.

Empirical justification for our findings is presented as a case exemplar, which serves to substantiate our theory development efforts regarding transnational offshore-intermediation. Focusing on a middleman such as I-Technologies allows us to zoom in on the role of an intermediary function in pure form, ${ }^{1}$ and to develop theory on what, how, and where software development tasks are performed. While we believe we make an important contribution to the literature on required intermediation capabilities in offshore software development, we leave open the questions of who, and in which legal form, an intermediation functions shall be best performed. As Field (2002) observes, the manin-the-middle may, but does not have to, be placed in separate legal entity as was the case with I-Technologies. At times, firms choose to internalize the middleman function to deal directly with offshore vendors. At other times, a global software vendor might assume the function by providing a local interface to clients, while internalizing project management functions for the vendor.

The market for offshore intermediaries is presently clustering towards two types, legal and operational. Both legal and operational intermediaries participate in pre- and post-contractual phases, although there is a clear tendency for the consultancies to focus on operations, where legal firms focus on vender search, contract specifications, monitoring, and termination. However, this is not an exclusive pattern.

\section{Limitations}

Our study has a number of limitations that deserve attention. First, our evidence is fairly limited and originates from a single organization, supplemented by market research. Moreover, our empirical understanding of this phenomenon is nascent at best. While several of the functions we identified are well understood (e.g. managing multiple vendors), offshore sourcing of knowledge-intensive software development services creates a series of new challenges and remedies. An interesting empirical question for future research is to what extent transnational intermediation capabilities are similar to the capabilities of traditional consultancies. Important similarities include that both businesses include knowledge management challenges 
future research in assessing the managerial implications of this trend. important differences. For example, while consultancies conventionally mediate between clients and the professional labor market, the transnational intermediary we studied mediates between clients and vendors in offshore locations.

Another significant limitation in our study is a lack of attention awarded to the relative costs of using an intermediary. It is well assumed that intermediaries realize financial compensation or economic rents when providing their services. This represents an accounting-based cost and can likely be partitioned in a comparative financial analysis of intermediated $v s$ direct exchanges. However, it is also well known that introducing a third party to a transaction introduces additional coordination and communication costs, which could have detrimental effects on the partnership. Given the nascent stage of the discourse on offshore intermediation, our analysis attempted to delineate the ostensible benefits. However, similar attention to the relative costs of intermediated exchanges can help balance our understanding as it matures.

\section{Future research}

Future research will benefit from larger sample sizes that allow empirical corroboration and increased theoretical advances that would help to focus and refine research efforts in this area. Moreover, as our empirical evidence is based in offshore systems development, we have focused our arguments on this task. However, that is only one business function with its associated processes. There is already a strongly growing market for Business Process Outsourcing in other areas from relatively routine functions (e.g. call centers, accounting, technical support) to knowledge intensive and innovation-centric research (e.g. financial services, medical services, management consulting, and $R \& D$ ) where the phenomenon of business process offshoring could prove very beneficial. In such research, the definition and verification of orthogonal properties, such as: (a) transaction antecedents, (b) generalizable properties of common processes, and (c) sector-specific variables, will be a useful guide for future research in transnational intermediation.

In addition, as mentioned previously, future research can benefit from an understanding of the differences between intermediaries and traditional consultancies, as well as a greater emphasis on the financial and non-financial-based costs of intermediated exchanges.

Finally, the boundary spanning literature highlights the dynamic, evolutionary nature of boundary spanning capabilities (Levina and Vaast, 2005). Specifically, boundary spanning capabilities can reside with a third party initially, but through time, may be transferred and acquired by the client and vendor. As such, a static view of offshore intermediation will ignore the knowledge transfer and learning effects that would surface in a lifecycle analysis. Future research could focus on the evolutionary nature of the relationship and study how these boundary spanning capabilities emerge or migrate at various loci within the relationship. Undoubtedly, the discourse on offshore intermediation is nascent. We hope that our framework and research propositions will prove useful for

\section{Note}

1 By pure form we mean that this company does nothing else than offshore intermediation. Other companies do bundle functions such as own software development and consulting with their offshore intermediating capabilities.

\section{References}

Ågerfalk, P. and Fitzgerald, B. (2006). Flexible and Distributed Software Processes: Old Petunias in new bowls? Communications of the ACM 49(10): 27-34.

Aldrich, H. and Herker, D. (1977). Boundary Spanning Roles and Organization Structure, Academy of Management Review 2(2): 217-231.

Allen, T.J. and Cohen, S.I. (1969). Information Flow in Research and Development Laboratories, Administrative Science Quarterly 4: 12-19.

Armbrüster, T. and Kipping, M. (2003). Strategy Consulting at the Crossroads. Technical Change and Shifting Market Conditions for Top-Level Advice, International Studies of Management and Organization 4: 19-42.

Argote, L. (1999). Organizational Learning: Creating, Retaining and Transferring Knowledge, Norwell, MA: Kluwer.

Barthelemy, J. (2001). The Hidden Costs of IT Outsourcing, Sloan Management Review 42(3): 60-69.

Barzel, J. (1982). Measurement Costs and the Organization of Markets, Journal of Law and Economics 25(1): 27-48.

Bechky, B.A. (2003). Sharing Meaning Across Occupational Communities: The transformation of understanding on a product floor, Organization Science 14(3): 312-330.

Boland, R.J. and Tenkasi, R.V. (1995). Perspective Making and Perspective Taking in Communities of Knowing, Organization Science 6(4): 350-372.

Booch, G. (1994). Object-Oriented Analysis and Design, Reading, MA: AddisonWesley.

Booch, G., Rumbaugh, J.E. and Jacobson, I. (1999). The Unified Modeling Language User Guide, Reading, MA: Addison-Wesley, 2000.

Carlile, P.R. (2002). A Pragmatic View of Knowledge and Boundaries: Boundary objects in new product development, Organization Science 13(4): 442-455.

Carlile, P.R. (2004). Transferring, Translating, and Transforming: An integrative framework for managing knowledge across boundaries, Organization Science 15(5): 555-568.

Cross, R.L. and Parker, A. (2004). The Hidden Power of Social Networks: Understanding How Work Really Gets Done in Organizations, Boston: Harvard Business School Press.

Cusumano, M. (2006). Envisioning the Future of India's Software Services Business, Communications of the ACM 49(10): 15-17.

Dedene, G. and DeVreese, J.P. (1995). Realities of Off-Shore Reengineering, IEEE Software 12(1): 35

Dyer, J. and Singh, H. (1998). The Relational View: Cooperative strategy and sources of interorganizational competitive advantage, Academy of Management Review 23(4): 660-679.

Earl, M. (1996). The Risks of Outsourcing IT, Sloan Management Review 37(3): 26-32.

Field, T. (2002). The Man in the Middle, CIO Magazine, 1st April, 2002 accessed on 10th February, 2007.http://www.cio.com/archive/040102/middle. html.

Glaser, B.G. (1992). Emergence vs. Forcing: Basics of Grounded Theory Analysis, Mill Valley, CA: Sociological Press.

Gopal, A., Mukhopadhyay, T. and Krishnan, M. (2002). The Role of Software Processes and Communication in Offshore Software Development, Communications of the ACM 45(4): 193-200.

Hammer, M. (1995). The Reengineering Revolution, New York, NY: HarperCollins.

Hofstede, G. (1980). Culture's Consequences: International Differences in Work Related Values, Newbury Park, CA: Sage.

Keil, M. and Mann, J. (2000). Why Software Projects Escalate: An empirical analysis and test of four empirical models, MIS Quarterly 24(4): 631-664. 
King, W.R. (2005). Outsourcing Becomes More Complex, Information Systems Management 22(2): 89.

Kogut, B. and Zander, U. (1992). Knowledge of the Firm, Combinative Capabilities, and the Replication of Technology, Organization Science 6(May-June): 383-397.

Lacity, M., Willcocks, L. and Feeny, D. (1995). Information Technology Outsourcing: Maximizing flexibility and control, Harvard Business Review, 6(May-June): 84-93.

Lane, P. and Lubatkin, M. (1998). Relative Absorptive Capacity and Interorganizational Learning, Strategic Management Journal 19(5): 461-477.

Lee, J.N. and Kim, Y.G. (1999). The Impact of Knowledge Sharing, Organizational Capability and Partnership Quality on IS Outsourcing Success, Journal of Management Information Systems 15(4): 29-61.

Lee, J.N., Miranda, S.M. and Kim, Y.M. (2004). IT Outsourcing Strategies: Universalistic, contingency, and configurational explanations of success, Information Systems Research 15(2): 110-131.

Levina, N. and Ross, J.W. (2003). From the Vendor's Perspective: Exploring the value proposition in IT outsourcing, MIS Quarterly 27(3): 331-364.

Levina, N. and Vaast, E. (2005). The Emergence of Boundary Spanning Competence in Practice: Implications for implementation of and use of information systems, MIS Quarterly 29(2): 335-363.

Mahnke, V. (2001). The Process of Vertical Dis-Integration: An evolutionary perspective on outsourcing, Journal of Management and Governance 5(3-4): 353-379.

Mahnke, V. and Overby, M.L. (2007). Coping with Failure Sources in $\mathrm{R} \& \mathrm{D}$ Consortia, International Journal of Technology Management 14(1) 13-35.

Mahnke, V., Overby, M. and Oscan, S. (2006). Make and/or Buy of IT-enabled Service Innovation, Industry and Innovation 13(2): 189-207.

Mahnke, V., Overby, M.L. and Vang, J. (2005). Strategic Outsourcing of IT Services: Theoretical stocktaking and empirical challenges, Industry and Innovation 12(2): 205-253.

Markus, H. and Kitayama, S. (1991). Culture and the Self: Implications for cognition, emotion, and motivation, Psychological Review 98(2): 224-253.

Miranda, S. and Kavan, B. (2005). Moments of Governance in IS Outsourcing. Conceptualization Effects of Contracts on Value Capture and Creation, Journal of Information Technology 20(3): 152-169.

Monteverde, K. and Teece, D. (1995). Technological Dialog as Incentive for Vertical Integration in the Semi-Conductor Industry, Management Science 41(10): 1624-1638.

Murthy, S. (2004). The Impact of Global Outsourcing on IT Providers, Communications of the AIS 14(article 25): 1.

Nahapiet, J. and Ghoshal, S. (1998). Social Capital, Intellectual Capital and the Organizational Advantage, Academy of Management Review 38(2): 242-266.

Pfannenstein, L.L. and Tsai, R.J. (2004). Offshore Outsourcing: Current and future effects on American IT industry, Information Systems Management 21(4): 72-80.

Rottman, J.W. (2006). Successfully Outsourcing Embedded Software Development, IEEE Computer 39(1): 55-61.

Rottman, J. and Lacity, M. (2004). Twenty Practices for Offshore Sourcing, MIS Quarterly Executive 3(3): 117-130.

Rousseau, P.L. and Wachtel, P. (1998). Financial Intermediation and Economic Performance: Historical evidence from five industrialized countries, Journal of Money, Credit and Banking 30(4): 657-678.

Rubinstein, A. and Wolinsky, A. (1987). Middlemen, Quarterly Journal of Economics 102(3): 581-594.

Rumbaugh, J.E., Blaha, M.R., Premerlani, W.J., Eddy, F. and Lorensen, W. (1991). Object-Oriented Modeling and Design, Englewood Cliffs, NJ: PrenticeHall.

Sahay, S., Nicholson, B. and Krishna, S. (2003). Global IT Outsourcing: Software Development Across Boarders, Cambridge, UK: Cambridge University Press.

SEI (2005). Software Engineering Institute. http://www.sei.cmu.edu/cmmi/ accessed on 12th January, 2007.

Sese, F., Wareham, J. and Bonet, E. (2006). Words and Objects in Information Systems Development: Six paradigms of information as representation, in Proceedings of the 14th European Conference on Information Systems, ECIS, Gothenburg, Sweden, 2006.

Spulber, D.F. (1999). Market Microstructure: Intermediaries and the Theory of the Firm, Cambridge, England, UK: Cambridge University Press.

Star, S.L. (1989). The Structure of Ill-structured Solutions: Heterogeneous problem-solving, boundary objects and distributed artificial intelligence, in:
M. Hans and L. Gasser (eds.) Distributed Artificial Intelligence, Vol. 2, Menlo Park, CA: Morgan Kaufman, pp. 37-54.

Strauss, A.L. and Corbin, J. (1990). Basics of Qualitative Research: Grounded Theory Procedures and Techniques, Newbury Park, CA: Sage.

Te'eni, D. (2001). A Cognitive-Affective Model of Organizational Communication for Designing IT, MIS Quarterly 25(2): 251-312.

Trompenaars, F. and Hampden-Turner, C. (1997). Riding the Waves of Culture: Understanding Diversity in Global Business, 2nd edn, New York: McGraw-Hill.

Tushman, M.L. and Scanlan, T.J. (1981). Boundary Spanning Individuals: Their role in information transfer and their antecedents, Academy of Management Journal 24(1): 286-305.

von Hippel, E. (1988). The Sources of Innovation, New York: Oxford University Press.

Wareham, J. and Gerrits, H. (1999). De-Contextualizing Competence: Can business best practice be bundled and sold? European Management Journal 17(1): 39-49.

Wareham, J, Mahnke, V., Bjørn-Andersen, N. and Peters, S. (2007). Communication Metaphors-in-Use: Technical communication and offshore systems development, IEEE Transactions on Professional Communication 50(2): 93-108.

Willcocks, L and Lacity, M. (1998). Strategic Sourcing of Information Systems: Perspectives and Practices, New York: John Wiley \& Sons Ltd.

Williamson, O.E. (1996). The Mechanisms of Governance, New York, New York, USA: Oxford University Press.

Zave, P. and Jackson, M. (1997). Four Dark Corners of Requirements Engineering, ACM Transactions on Software Engineering and Methodology 6(1): $1-30$.

\section{About the authors}

Volker Mahnke is a professor of Strategic Management of IS at Copenhagen Business School. His research focuses on the intersection of information technology, economics and strategy. Dr. Mahnke's research has appeared in over 60 papers. Outlets included journals as IEEE Transactions on Professional Communication, Journal of Management Studies, Management International Review, International Journal of Technology Management, Journal of Management and Governance, Academy of Management Best Paper Proceedings and many others. His current research interest is focused on the interface between advances in ICT and business development as well as outsourcing of knowledge intensive work.

Jonathan Wareham is a professor of Information Systems at ESADE - University of Ramon Llull. His research focuses on the intersection of information technology, economics and strategy. Dr. Wareham's research has been published or forthcoming in such journals and proceedings as MIS Quarterly, IEEE Transactions on Engineering Management, IEEE Transactions on Professional Communication, IEEE Computer, Communications of the ACM, Telecommunications Policy, Journal of Information Technology, Information and Organization, and many others. He was awarded the Myron T. Green Outstanding Teaching Award, Georgia State University, in 2003. He was recently appointed as Associate Editor for Information Systems Research.

Niels Bjørn-Andersen is Professor in InformationSystems at the Center for Applied ICT at Copenhagen Business School. He has published more than 200 publications including articles in journals like Communications of the $A C M$, Communications of AIS, European Journal of IS, Information and Management, Information Systems Journal, Journal of MIS, Journal of Strategic IS, and TIMS 
Studies in the Management Science. He was the president of the global Association for Information Systems (AIS) in 1996, and received its distinguished AIS-LEO award in 2006. Current research interests include two large multinational research projects: (1) ITAIDE on development of new e-Customs systems for reducing fraud, enhancing security and minimizing administrative costs together with IBM and SAP among 15 other organizations, and (2) 3gERP project on development of next generation of ERP-systems for the SME market with Microsoft. 